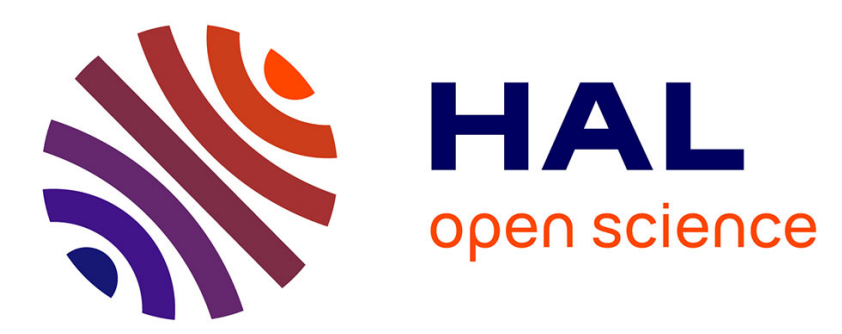

\title{
A fuzzy approach for competency characterisation based on a work situation analysis.
}

\author{
Farouk Belkadi, Eric Bonjour, Maryvonne Dulmet
}

\section{To cite this version:}

Farouk Belkadi, Eric Bonjour, Maryvonne Dulmet. A fuzzy approach for competency characterisation based on a work situation analysis.. 9th Symposium IFAC on "Automated Systems Based on Human Skill and Knowledge", ASBHS'06., May 2006, Nancy, France. 6 p. hal-00331732

\section{HAL Id: hal-00331732 \\ https://hal.science/hal-00331732}

Submitted on 17 Oct 2008

HAL is a multi-disciplinary open access archive for the deposit and dissemination of scientific research documents, whether they are published or not. The documents may come from teaching and research institutions in France or abroad, or from public or private research centers.
L'archive ouverte pluridisciplinaire HAL, est destinée au dépôt et à la diffusion de documents scientifiques de niveau recherche, publiés ou non, émanant des établissements d'enseignement et de recherche français ou étrangers, des laboratoires publics ou privés. 


\title{
A Fuzzy Approach for Competency
}

\section{Characterisation Based on a Work Situation Analysis}

\author{
F. Belkadi, E. Bonjour, M. Dulmet \\ Laboratoire d'Automatique de Besançon \\ UMR CNRS6596 - ESMM/UFC \\ 24, rue Alain Savary 25000, Besançon \\ fbelkadi@ens2m.fr - ebonjour@ens2m.fr - $\underline{\text { mdulmet@ens2m.fr }}$
}

\begin{abstract}
The purpose of this work is to give a decision support to meet requirements in competencies management. We assume that the building, the development, and the use of each competency need the concurrence of different kinds of interactions in the real work situation. The competency characteristics can be evaluated by an expert within an analysis of work situation, to get an interpretation of these interactions. In this sense, we propose a qualitative method of competency characterisation based on a formal representation of the situation. The aim of this paper is not to give all mathematical details of a fuzzy approach but rather to present how qualitative knowledge about the situation can be used to characterise associated competency.
\end{abstract}

Keywords: Modelling, work situation, competencies, qualitative method, and fuzzy approach.

\section{Introduction}

The question of characterisation and selection of strategic competency is of a great interest for competitive industry (Sohel \& al., 2003). An enterprise has to be seen nowadays to be a producer of specific distinctive competencies. However, it is difficult to find effective solutions for competencies management without interest to associated knowledge composing this competency, since knowledge and competency are often hidden in the cognitive perspective.

As with knowledge management, there are many requirements that fall within the field of competency management, such as identification of the competencies required by the enterprise's activities and those acquired by the employees, development of this capital and being sure of its timely availability, and finding the mechanisms that will mean these competencies evolve to meet the needs for innovation and competition.

Organisations these days are becoming more and more aware of the strong connection between these two cognitive concepts and are seeking ways to integrate them at the same time (knowledge management (Studer \&al., 1998) and competency management) in order to protect and develop their experience (Vasconcelos \&al., 2000).
Several studies in Knowledge Management (KM) and traceability techniques like activity organisation have been used as a basis for the identification and management of a competency, which is activated during an activity. The management and choice of variables relevant to the activity should be based on formal models. These variables must be able to be observed and measured in the work situation.

In this article, we aim at characterising competency (acquired by an actor or required by business processes), through an analysis of work situations. In section 2, we consider the main characteristics of competency through a brief literature review. In section 3, we propose a novel approach to assist with competency characterisation. Section 4 presents the fundamental concepts and finally, section 5 describes the use of fuzzy logic for the need of competency characterisation.

\section{The concept of competency}

Several definitions were given to the concept of competency. Le Boterf (2000) has defined competency as "a result of a combination of several individual resources and of resources from the environment". For Grundstein (2002) it is: " the capacity of individuals to put into play, over and beyond their own knowledge, physical resources 
and know-how constituting their knowledge of the enterprise in a work environment: constraints, etc". Drejer (2001) defines competency as" a system of human beings, using hard technology in an organised way and under the influence of a culture to create an output that yields a competitive advantage for the firm". For Tobias (2003): "competency is a set of personal characteristics (knowledge, skills, abilities) which are relatively stable across different situations" and Rosemary (2000) defines competency as "the degree to which individuals can apply the skills and knowledge associated with a profession to the full range of situations that fall within the domain of that particular profession". Torkkeli (2002) considers competency as cross-functional integration and coordination of capabilities. Capabilities refer to the actor's (or enterprise's) ability to exploit its resources.

Despite their differences, these definitions highlight the key characteristics of competency:

- Competency is a combination which goes beyond a simple possession of resources;

- It depends on the conditions in which it is activated (or even on the situation);

- Its organisation is relatively stable across a full range of situations.

These characteristics are fundamental to understanding and emphasising the close relationship between competency and the work situation. Each of these definitions is based on a particular model of competency, which depends on the field it is related to and the specific needs it is addressing for that field. We have pointed out the general aspects of competency model (Bonjour \& al., 2002), the first one is the situation identification where the actor perceives and constructs relevant knowledge about his work context, these knowledge give a qualitative description of the situation properties (importance, complexity, familiarity,...). These properties guide the decisionmaking which generates the real action and the competency performance level to carry out during the activity achievement. The second aspect concerns the structure of this competency, its components and the interdependencies between these components.

According to the characteristics listed above, we define the concept of competency as: "the mobilisation and dynamic organisation of a set of heterogeneous cognitive resources that lead to the production of an acknowledged performance, in relation to a given situation and in the context of a finalized activity".

We assume that elaborating a competency model needs to get a formal representation of the work situation and also, a subjective qualification of this situation to define its properties.

\section{Competency characterisation from the analysis of work situation}

\subsection{Overview}

In recent years a number of formal methods have been developed in industrial engineering to facilitate the work of decision-makers in their management of projects and human resources (Tsai \&al., 2003). (Stenlund \&al. 1999) have summarised the general process of competency management as covering several functions. The characterisation of competency model presents a first step of this process.

Many of these methods are used for the identification of "core competencies" in an enterprise (Pu \&al., 2003). Pépiot \& al. (2005) propose a method, based on fuzzy logic, to recognize the value of competencies that are crucial to an enterprise. The fuzzy methods (Zadeh 1965) are also used by (Boucher \&al., 2003) to cope with the problem of competency modelling and the development of performance indicators that integrate the concept of competency in the management of industrial organisations.

Today new information and communication technologies provide a useful media for the development of tools for use in competency management. For example, Harzallah, \&al. (2002) suggest constructing an information system specifically for the formalisation and use of individual competencies in the maintenance department of an industrial enterprise. The identification and indexing of competencies involve identifying various competencies and organising them in reference systems. Creating this type of reference system is done by Human Resources experts on the basis of an analysis of the requirements of the work situations (Rault-Jacquot, 1993).

However, little interest is given to formal methods oriented to "competencies characterisation" from the situation analysis (Vidal \&al., 2002).

Our work concerns competency characterisation through analysis of work situations using formal tools to make the connection between competency and situation (traceability of activities). The choice of fuzzy methods is motivated by the need to clarify the expert's reasoning in charge of competency management so that this activity can be at least partially automated. The next section develops this proposition. The aim of this paper is not to describe the formal model of situation (Belkadi \& al, 2004).

\subsection{General approach}

The generic approach of the characterisation method is described in the following figure. The aim is to give a support to collect relevant information about an activity, to analyse this 
information in its context and finally and to give orientation for the characteristics of the associated competency.

Our global approach is split up into four steps. Each step is supported by a specific module, which is integrated in the architecture of the global system for competency characterisation:

1. The first step concerns the collection and the classification of activity information and its related situation. This step needs to develop a traceability system, structured by a situation model (Belkadi \&al., 2004), to keep history of activity evolution. The module called "knowledge of the situation" brings together all the knowledge about the modifications made to the situation as a result of the realisation of an activity, the organisation of the activity, the constraints, the relationships between actors ...

2. The second step aims at analysing the stored information to get a characterisation of the situation regarding to specific indicators. These indicators are resulting in a detailed description of the work situation as: complexity, stability, and level of cooperation. The module called "situation characterisation" contains this new form of knowledge deduced as a set of qualitative variables and evaluated regarding to the expert point of view.

3. The third step concerns the use of qualitative knowledge about situation to get a formal characterisation of associated competency. This step needs to describe the different connections between situation and competency components. The module called "fuzzy characterisation of competencies" uses fuzzy inference rules to present the previous connections and to automate the expert's reasoning concerning his task of competency characterisation.

4. In the fourth step, a model to organise competency can be used as a basis for classifying the data in the competency reference system. This model is consistent with the theoretical model of the activation of competency and deals with the different components of the competency (Bonjour \&al., 2002).

Since the description of situation model and the theoretical model of competency are detailed in previous publications (Belkadi \& al. 2004), (Bonjour \& al., 2002), the scope of this paper focuses on the answer of the steps 2 and 3 . Specially, we present propositions about how to use the fuzzy theory to cope with these needs.

\section{Fundamental concepts}

\subsection{About the situation model}

(Belkadi \&al. 2004) defined the concept of work situation as follows: "a situation is a set of various entities and of various interactions (of different kinds) globally describing the external environment in which an actor mobilises his competencies". We have proposed to represent a work situation through three main concepts: basic entities, interactional entities and specific roles. These concepts allow for representation of knowledge about the situation through levels of abstraction. Entity is a generic concept that is used to represent all the physical elements of the situation (basic entities) in addition to the interactions between these elements (interactional entities). It concerns all activities, transactions, constraints, work community.

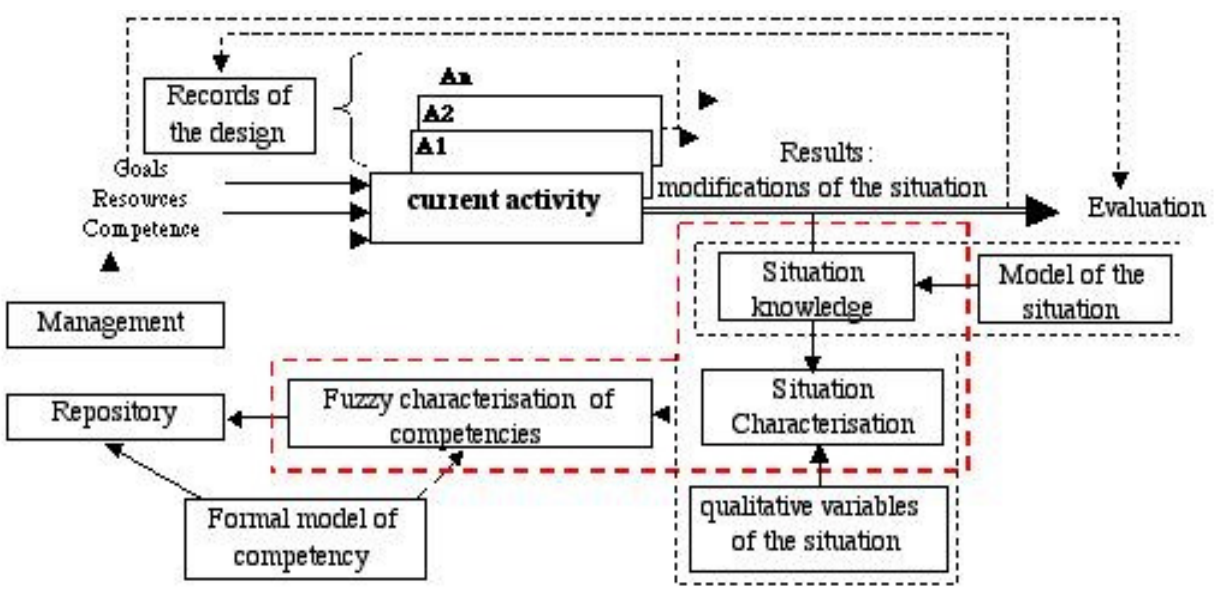

Figure 1: A general outline of our approach 
The concept of role is considered as a new type of instant relationship that expresses the contribution made by each element in a particular interactional entity at a given moment. We have distinguished five kinds of roles:

The "actor" who/which participates directly in the interaction and who/which is responsible for the end result,

The "customer" who/which received the end result of the interaction.

The "manager" who/which regulates functioning of an interaction (IE).

The "support" who/which assists and give help in the realisation of the interaction.

The "object" concerns every entity on who/which the interaction (IE) acts.

To cope with our needs, some relevant views are interesting to qualify the situation. For example, we can consider the different views as follow:

- The task goals describing different goals, and its related constraints.

- The context view describing different elements of the work context: object, resources, collaborators.

- The activity organisation concerning the action plan that guides the activity realisation. The action plan contains a set of structured actions. It is a description of the manner with which the actor intends to reach the task goals.

- The action view concerning the different actions really producing during the activity, two main kinds of action will be distinguished: External action, which has an effect on at least one object of the external situation with respect to the actor, and internal action that implies a modification in the action plan (a new action, the deletion of another action, etc)

- The activity result concerning all new entities: new object, new constraint, information exchange, resource modification, ...

\subsection{Components of competency}

To make out the dependence between situation and competency, we propose to describe a competency through a set of technical knowledge linked to performance levels (or expertise level) and a specific signature of competency with respect to cognitive factors and action rules. We consider the following components of competency with respect to the theoretical model:

\section{-Technical capacities}

Related to what is needed to perform a task and to deal with the concerning entities during the activity with assumption to the role of each entity in this activity.

\section{- Cognitive capacities}

In contrast to the first category, cognitive capacities are difficult to express explicitly but they can be qualified in relation to the task complexity and the context in which it is carried out. Two types of cognitive capacities are considered:

"reflection/analysis" and "organisation" capacities. The former type is concerned with capacities required to perceive and analyse a current situation, and to be able to extract information from it, that is, relevant to the actor's work through his interaction within the situation. The latter type relates to the minimum effort required by an actor to organise his work and resources and to prioritise the various actions constituting the activity

They are represented by a signature value: NCC.

\section{- Action rules}

These components are related to performing tasks in a real situation. Two types are also considered: - Decision-making and reactive aspects: refers to the capacity to react when faced with unexpected events in the situation. They are represented by a signature value: NRA.

- Relationship aspects: are concerned with the actor's behavioural aspects when he interacts with other actors. It covers the nature of exchanges.

\section{Competency characterisation}

\subsection{Situation characterisation}

General situation features can be deduced from these different views with qualitative variables. The qualification of these variables is obtained regarding to the importance of this context element for the mobilised competency. For example, we can suppose that the organisational effort necessary is in direct proportion to the number of elements the actor has to take into account to carry out his activity.

The following table (table 1) sets out a nonexhaustive list of the possible environmental factors entailed in the competency mobilised.

The evaluation of the different parameters that are characteristic to a situation is quite qualitative and subjective, and it mainly depends on the general context of the person making the judgement. For example, an expert could consider that the number of participants in a cooperative action is high, if the number is higher than 8 and the total number of staff present is 10 . This evaluation would of course be lowered if there were the same number of participants in a setting, where there were actually 100 active staff members.

We associate the situation features with each of the situation elements as defined in table 1. These features may have quantifiable values such as, the number of interactions during the activity or the number of constraint 


\begin{tabular}{|l|l|}
\hline $\begin{array}{l}\text { Type of } \\
\text { competency }\end{array}$ & Situation items in action \\
\hline $\begin{array}{l}\text { Technical } \\
\text { capacities }\end{array}$ & $\begin{array}{l}\text { Entities in interaction during the } \\
\text { activity }\end{array}$ \\
\hline $\begin{array}{l}\text { Technical } \\
\text { Capacities level } \\
\text { (required or } \\
\text { necessary) }\end{array}$ & $\begin{array}{l}\text { Nature of the reference task } \\
\text { Importance of the entity in } \\
\text { relation to the interaction (the } \\
\text { activity) ... }\end{array}$ \\
\hline Analysis NCC & $\begin{array}{l}\text { Nature of the activity } \\
\text { Complexity of the task in relation } \\
\text { to the clarity of the objectives } \\
\text { Complexity of the main object } \\
\text { treated by the analysis action }\end{array}$ \\
\hline $\begin{array}{l}\text { Organisation } \\
\text { Nee - }\end{array}$ & $\begin{array}{l}\text { Complexity in relation to the } \\
\text { totalnumberofentities acturily } \\
\text { dealt with } \\
\text { Complexity depending on the } \\
\text { number of actions }\end{array}$ \\
\hline $\begin{array}{l}\text { Decision- } \\
\text { making NRA }\end{array}$ & $\begin{array}{l}\text { Nature of the activity } \\
\text { Level of constraints } \\
\text { Scope of the task }\end{array}$ \\
\hline $\begin{array}{l}\text { Relationship } \\
\text { NRA }\end{array}$ & $\begin{array}{l}\text { Main type of relationship } \\
\text { Number of participants }\end{array}$ \\
\hline
\end{tabular}

Table 1. Relationship between situation and competency

Fuzzy concepts can be used to resolve the characterisation process. The general architecture of this kind of system is given by the following stages.

\subsection{Fuzzyfication stage}

The fuzzyfication stage involves associating linguistic variables with different situation features and representing them through membership functions that express the estimation given to the value of a variable.

For example, the complexity of the main object, associated to the competency "level of analysis" (table 1) can be evaluated qualitatively by an appreciation of the number of elements really associated to this object (or composing it). We associate to this property the linguistic variables: easier (E), relatively complex (R.Cx.), complex (CX). This concept is presented in the fuzzyfication stage by the membership functions in Figure2.

Similarly, the range of elementary actions can give the qualification of the nature of activity. In the case of the competency "level of analysis", we focus on the range of analysis action containing in this activity. We can choose the fuzzy values: different (D), relatively close (R.Cs), and close (Cs), for the proximity of the activity to the action analysis.

For the output, we can define the following fuzzy value of the linguistic variable "analysis level": low $(\mathrm{L})$, medium $(\mathrm{M})$, high $(\mathrm{H})$, very high $(\mathrm{VH})$.

0.33 characterises a number of elements.

0 . 45 and 0.55 represente a degree of belief.

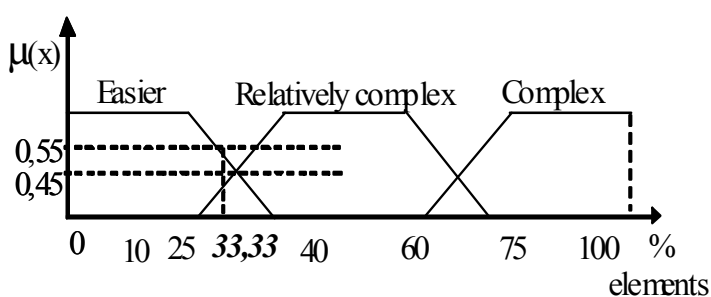

Figure 2: Example of membership function

\subsection{Inference stage}

The passage from the situation characteristics to the determination of associated competency is based on a set of inferences rules. An inference rule is given as: (If Antecedents Then Consequences )

Here "antecedent" covers the various situation features, while "result" contains an evaluation of the component of the competency according to the previous definition.

The inference stage is applied to all the situation features and its related components of competency. The description of the inference rules is obtained regarding to the analysis of relation between situation features and related competencies.

For example, the relation between the competency "analysis level" and the associated features of situation can be obtained by the following rules (not exhaustive) : N.A.: Nature of activity, AL: Analysis Level, Cpx: Complexity

IF Cpx IS Cx. AND N.A. is Cs THEN AL. IS VH.

IF Cpx IS R.Cx AND NA. is RCs THEN AL IS H

IF Cpx IS E AND N.A. is D. THEN A.L. IS L.

The inference mechanism links the input variables to the output variables by some operations (max,min), (max,prod) (Zadeh 1965). The final result is a new membership function traducing the whole rules. We chose this method because we think that it reflects experts reasoning on competences characterisation.

\subsection{Defuzzyfication stage}

The final stage involves finding a value for the competency from the resulting membership function. We used the method of center of gravitythe At the end, a quantitative or qualitative value is given to the considered component. This value is obtained from final membership function of the output after inference of all concerned rules.

\section{Conclusion}

Starting from the fundamental hypothesis according to which, competency cannot be defined independently of situation, we have proposed a general approach to the characterisation of competencies through the characteristics of work situations. This paper has aimed at showing how to 
use frequently ill-defined knowledge about the work situation for the purpose of competency management. The choice of inference rules and of situation features is neither exhaustive nor final but it has to rely on coherent and global models. It can be adapted to needs and to a particular field of study. The generic concepts of entities and interactions developed in our situation model on the one hand, and the architecture of scheme activation developed in our competency model, on the other hand, provide a great interest for this need.

Our work is open to being improved upon and to being tested. It also opens perspectives for research into approaches to team building (choice of team members being based on their competencies).

\section{References}

Belkadi F., Bonjour E., Dulmet M. "Proposition of a Situation Model in View to Improve collaborative" INCOM'2004: $11^{\text {th }}$ Symposium on Information Control Problems in Manufacturing, Salvador-Bahia, Brazil 5-7 April 2004.

Bonjour E., Dulmet M., Lhote F., "An internal modelling of competency, based on a systemic approach, with socio-technical systems management in view" IEEE Conference on Systems, Man and Cybernetics, October 6-9, 2002 hammamet Tunisia

Boucher X., Burlat P. : "Vers l'intégration des compétences dans le système de performances de l'entreprise", Journal Européen des Systèmes Automatisés (JESA), Vol. 37, n³, pp 363-390, septembre 2003.

Drejer A. "How can we define and understand competencies and their development ?" Technovation 21 Elsevier Science (2001) 135146

Grundstein M «De la capitalisation des connaissances au renforcement des compétences dans l'entreprise étendue $» 1^{\text {er }}$ colloque du groupe de travail gestion des compétences et des connaissances en génie industriel, Nantes le 12-13 décembre 2002

Harzallah M. Vernadat. F. "IT-based competency modeling and management: from theory to practice in entreprise engineering and operations" Computer in industry 48 Elsevier Science (2002) 631-644

Le Boterf G. "Construire les compétences individuelles et collectives », Editions L'organisation 2000

Pepiot G., Cheikhrouhou N., FÄurbringer J-M., and Glardon R., "A fuzzy approach for the valorisation of the competencys", International Conference on Industrial Engineering and Systems Management IESM 2005, May 16 - 19, Marrakech (Morocco)

Rault-Jacquot V., «Contribution à la valorisation du patrimoine technologique de l'entreprise : proposition d'une approche d'inventaire et de l'évaluation des compétences » Thèse de doctorat génie des systèmes industriels INP de Loraine, Nancy, décembre 1993.

Pu Q., Xia H., Wu Z., Liao Y. "The Application of the System Parameter Fusion Principle to Evaluating the Core Competency of the Corporation" Information Reuse and Integration, 2003. IRI 2003. IEEE International Conference

Rosemary M. Lysaght, James W. Altschuld "Beyond initial certification: the assessment and maintenance of competency in professions" Evaluation and Program Planning 23 Elsevier Science (2000) 95-104

Sohel A., Schroeder R. G., "The impact of human resource management practices on operational performance: recognizing country and industry differences" Journal of Operations Management 21 Elsevier Science (2003) 19-43

Stenlund K.L., Hörte S-A., "Cometence Accounting-Methods for Measuring and Valuing Key-cometencies" the European Operations Management Association VI International Annual Conference "Managing Operations Networks", 7-8 June 1999, Venice, Italy

Studer R.,, Benjamins V. R.,, Fensel D., "Knowledge Engineering: Principles and methods" Data \& Knowledge Engineering 25 21 Elsevier Science (1998) 161-197

Tobias L. Dietrich A. "Identifying Employee Competencies in Dynamic Work Domains: Methodological Considerations and a Case Study" Journal of Universal Computer Science, vol. 9, no. 12 (2003), 1500-1518

Tsai H-T., Moskowitz H., Lee L-H., "Human resource selection for software development projects using Taguchi_s parameter design" European Journal of Operational Research 151 Elsevier Science (2003) 167-180

Torkkeli M., Tuominen M., "The contribution of technology selection to core competencies", Int. J. Production Economics 77 Elsevier Science (2002) 271-284

Vasconcelos J., Kimble C., Gouveia F., Kudenk D. "A Group Memory System for Corporate Knowledge Management: An Ontological Approach" Proceedings of the 1st European Conference on Knowledge Management (ECKM'2000) Bled School of Management, Slovenia, October 2000, pp. 91-99.

Vidal-Gomel C., Samurçay R., "Qualitative analyses of accidents and incidents to identify competencies. The electrical systems maintenance case" Safety Science 40 Elsevier Science (2002) 479-500

Zadeh, Lotfi A. 1965. «Fuzzy Set». Information and Control, vol. 8, p. 338-35. 